\title{
A computational and experimental study of coflow laminar methane/air diffusion flames: Effects of fuel dilution, inlet velocity, and gravity
}

\author{
S. Cao ${ }^{\mathrm{a}, *}$, B. Ma ${ }^{\mathrm{a}, 1}$, B.A.V. Bennett ${ }^{\mathrm{a}}$, D. Giassi' ${ }^{\mathrm{a}}$, D.P. Stocker ${ }^{\mathrm{b}}$, F. Takahashic ${ }^{\mathrm{c}}$, M.B. Longa ${ }^{\mathrm{a}}$, M.D. Smooke ${ }^{\mathrm{a}}$ \\ ${ }^{a}$ Department of Mechanical Engineering E Materials Science, Yale University, P.O. Box 208284, New Haven, Connecticut 06520-8284 USA \\ ${ }^{b}$ NASA Glenn Research Center, Cleveland, Ohio 44135 USA \\ ${ }^{c}$ National Center for Space Exploration Research on Fluids and Combustion, NASA Glenn Research Center, Cleveland, Ohio 44135 USA
}

\begin{abstract}
The influences of fuel dilution, inlet velocity, and gravity on the shape and structure of laminar coflow $\mathrm{CH}_{4}$-air diffusion flames were investigated computationally and experimentally. A series of nitrogen-diluted flames measured in the Structure and Liftoff in Combustion Experiment (SLICE) on board the International Space Station was assessed numerically under microgravity $(\mu \mathrm{g})$ and normal gravity $(1 \mathrm{~g})$ conditions with $\mathrm{CH}_{4}$ mole fraction ranging from 0.4 to 1.0 and average inlet velocity ranging from 23 to $90 \mathrm{~cm} / \mathrm{s}$. Computationally, the MC-Smooth vorticity-velocity formulation was employed to describe the reactive gaseous mixture, and soot evolution was modeled by sectional aerosol equations. The governing equations and boundary conditions were discretized on a two-dimensional computational domain by finite differences, and the resulting set of fully coupled, strongly nonlinear equations was solved simultaneously at all points using a damped, modified Newton's method. Experimentally, flame shape and soot temperature were determined by flame emission images recorded by a digital color camera. Very good agreement between computation and measurement was obtained, and the conclusions were as follows. (1) Buoyant and nonbuoyant luminous flame lengths are proportional to the mass flow rate of the fuel mixture; computed and measured nonbuoyant flames are noticeably longer than their $1 \mathrm{~g}$ counterparts; the effect of fuel dilution on flame shape (i.e., flame length and flame radius) is negligible when the flame shape is normalized by the methane flow rate. (2) Buoyancy-induced reduction of the flame radius through radially inward convection near the flame front is demonstrated. (3) Buoyant and nonbuoyant flame structure is mainly controlled by the fuel mass flow rate, and the effects from fuel dilution and inlet velocity are secondary.
\end{abstract}

Keywords: laminar coflow diffusion flame, gravity, fuel dilution, inlet fuel velocity, flame shape and structure

\section{Introduction}

Diffusion flames exist in most practical combustors, and an accurate understanding of their structure is crucial to efficiency improvement and pollution suppression. A coflow laminar diffusion flame, which has welldefined boundary conditions, is the simplest configuration from which interactions between flow field and reactions can be readily modified and studied [1]. Knowledge obtained from coflow laminar diffusion flames is not only of fundamental importance, but also can facilitate the study of turbulent diffusion flames in practical industrial combustors [2].

Microgravity provides an ideal environment for flame research. Compared to their counterparts in normal

\footnotetext{
*Corresponding author. FAX: +1 2034326775

Email address: su.cao@yale.edu (S. Cao)

${ }^{1}$ Currently at GE Global Research.
}

gravity, microgravity flames generally have larger temporal and spatial scales, they are exempt from intrusions of buoyancy forces, and they can be studied over a wider range of flame conditions. Over the past few decades, a significant amount of research has been conducted in microgravity, and the effects of various parameters on flame shape, structure, stabilization, and sooting behavior have been extensively studied (e.g., [3-11]).

In this work, previous computational and experimental investigations of coflow laminar diffusion flames (e.g., $[8,9])$ were further extended to characterize the effects of fuel dilution, inlet velocity, and gravity. The present work's objectives are: (1) to obtain an enhanced understanding of the influences of fuel dilution, inlet velocity, and gravity on the flame structure; and (2) to assess the accuracy of the numerical model by comparing computational and experimental results.

November 13, 2014 


\section{Burner configuration}

The burner consists of a central jet, from which the fuel mixture issues, and a surrounding coaxial square duct, from which the coflow air flows. The inner jet's inner radius is $r_{\mathrm{I}}=0.162 \mathrm{~cm}$ and its wall thickness is $w_{\text {JET }}=0.028 \mathrm{~cm}$. The outer square duct's width is $7.62 \mathrm{~cm}$. Details of the burner construction and operation are provided in a companion paper [12]. Eighteen flames have been studied under both microgravity $(\mu \mathrm{g})$ and normal gravity ( $1 \mathrm{~g}$ ) (36 flames total): three fuel dilution levels $\left(40 \%, 70 \%\right.$, and $100 \% \mathrm{CH}_{4}$ in mole fractions) and six inlet velocities (approximately 24, $46,55,64,80,89 \mathrm{~cm} / \mathrm{s}$, changing slightly at different fuel dilutions). Since each flame is surrounded by an air coflow and takes at most $5 \%$ of the cross-sectional area of the burner, the square duct is approximated as a coaxial tube with an identical cross-sectional area (radius $r_{\mathrm{O}}=4.288 \mathrm{~cm}$ ); see Fig. 1 (left). The velocity profile of the fuel stream is parabolic, with the average Reynolds number in the fuel jet ranging from 15 to 87 . Due to hardware imperfections, the flow field of the coflow air is not perfectly flat and has a bump near the inner tube; see Fig. 1 (right). To capture this nonideality, the measured inlet velocity distribution has been fitted as $v_{z}(r)=v_{0}\left[1-\tanh \left(\left(r-0.67 r_{\mathrm{I}}\right) / 0.038 \mathrm{~cm}\right)\right]+$ $13.50\left[0.5+0.5 \tanh \left(\left(r-1.1\left(r_{\mathrm{I}}+w_{\mathrm{JET}}\right)\right) / 0.09 \mathrm{~cm}\right)-\right.$ $\left.\exp \left(\left(r-r_{\mathrm{O}}\right) / 0.240 \mathrm{~cm}\right)\right]+3.16[\tanh ((r-0.44) / 0.15 \mathrm{~cm})+$ $\tanh ((0.96-r) / 0.35 \mathrm{~cm})]$, where the coefficient $v_{0}$ is determined numerically to match the inlet mass flow rate of the fuel mixture specified in the experiments. Since temperature measurements near the fuel tube exit are unavailable, the inlet temperature is set to $298 \mathrm{~K}$.

\section{Computational approach}

The numerical framework is similar to those in the authors' previous works (see, for example, [1316]) with the MC-Smooth vorticity-velocity formulation [17] employed. The gas is assumed Newtonian and diffusion is Fickian; the $n^{\text {th }}$ species diffusion velocity is calculated using detailed mixture averaging. The Soret and Dufour effects are neglected. The flow's small Mach number implies that the pressure field can be obtained via the ideal gas law. All thermodynamic, chemical, and transport properties are evaluated using vectorized and highly efficient libraries [18]. The gasphase chemistry is the GRI 3.0 mechanism [19] with all nitrogen-containing species (except $\mathrm{N}_{2}$ ) removed, leaving 35 species and 217 reactions. Certain reactions related to benzene and associated species (see Table 1
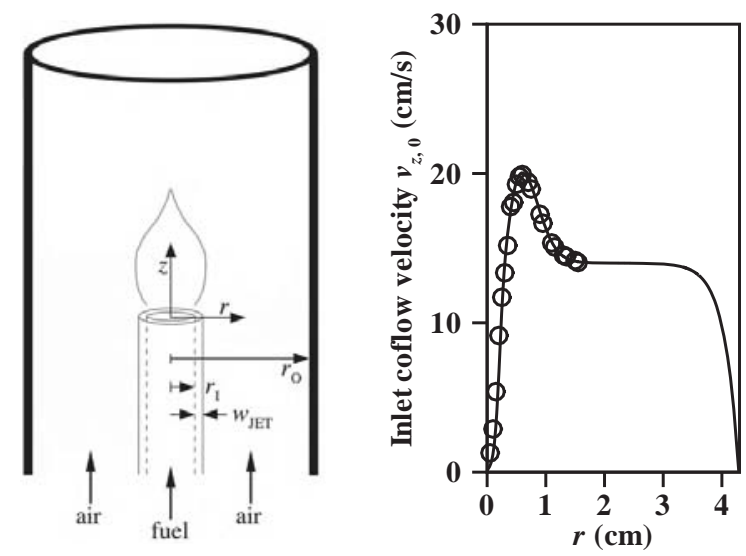

Figure 1: Left: Schematic of the burner used in the simulations. Right: Measured (circles) and fitted (line) velocity profiles of the coflow air.

of [20]) were added to allow the simulation of the sooting process in the $70 \% \mathrm{CH}_{4}$ and $100 \% \mathrm{CH}_{4}$ flames, with the augmented mechanism containing 42 species and 250 reactions. Since the maximum soot volume fraction of all flames is $0.22 \mathrm{ppm}$, effects of radiation reabsorption are insignificant $[15,16,21]$, and the power radiated from soot and gas bands $\left(\mathrm{CO}, \mathrm{CO}_{2}\right.$, and $\left.\mathrm{H}_{2} \mathrm{O}\right)$ is evaluated in the optically thin limit $[22,23]$.

A two-dimensional computational domain is employed with $r_{\max }=4.288 \mathrm{~cm}$ and $z_{\max }=12.200 \mathrm{~cm}$. Other than approximating the square duct as a tube, all boundary conditions are specified to reflect corresponding experimental conditions. The domain is spanned by a nonuniform $129 \times 202$ tensor product grid with points clustered towards the burner surface and the centerline to capture sharp gradients. The governing equations and boundary conditions are discretized by a nine-point finite difference stencil, and the resulting set of fully coupled, strongly nonlinear equations is solved simultaneously at all points using a damped, modified Newton's method [24, 25] and a nested Bi-CGSTAB linear algebra solver [26]. Pseudo-transient continuation is performed to aid in convergence of Newton's method, and each flame is solved to a Newton tolerance of $10^{-4}$. All calculations were performed on workstations with 3.0$\mathrm{GHz}$ processors, and the typical memory usage for a sooty flame simulation is around 5.5 GB of RAM.

\section{Experimental approach}

A digital single lens reflex camera was used for flame shape measurement and was fully characterized as a ratio pyrometer for soot temperature measurement. The 


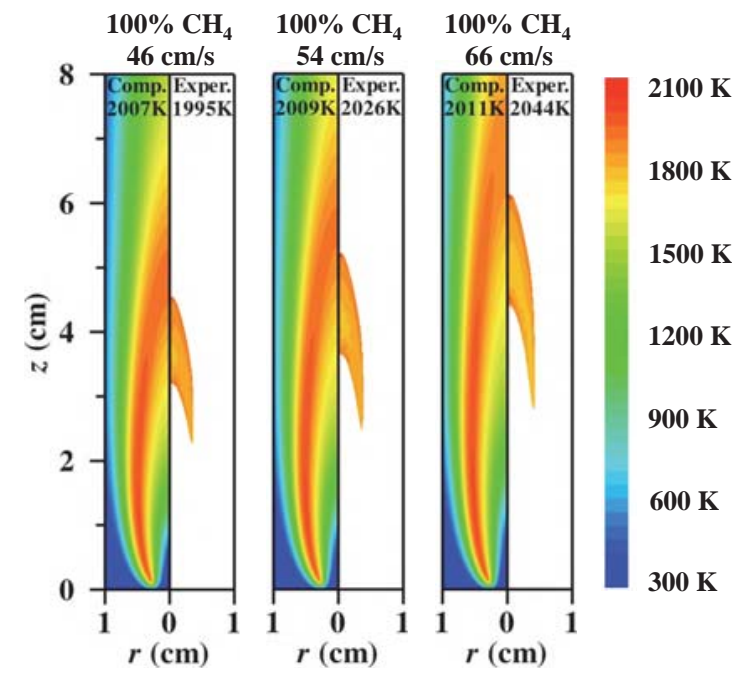

Figure 2: Typical results of computed flame temperature and measured soot temperature illustrating effects of inlet velocity. Flame parameters and maximum temperatures are shown at the top of each plot. Measured temperatures are only available in sooting regions.

spectral responses of the red, green, and blue channels have been measured following the approach detailed in $[27,28]$. A calculated lookup table that correlates color ratio and soot temperature is used to determine the axisymmetric soot temperature distribution. Details are reported in a companion paper [12].

\section{Results and discussion}

The numerical model has been validated for buoyant and nonbuoyant coflow laminar diffusion flames in previous research $[8,9]$. In this work, additional validation was conducted by comparing the computed and measured temperature fields and luminous flame shapes of a series of $\mathrm{CH}_{4}$-air coflow laminar diffusion flames in both $\mu \mathrm{g}$ and $1 \mathrm{~g}$. In Fig. 2, portions of the computed temperature fields and measured soot temperatures (available in the sooting region only) of the buoyant $100 \% \mathrm{CH}_{4}$ flames with increasing inlet velocity are shown. Results in Fig. 2 indicate very good agreement between computed and measured temperature profiles: their shapes and magnitudes are modeled accurately, and the influences of varying inlet velocity are correctly captured. The largest discrepancy between the measured maximum temperatures and corresponding predictions is $33 \mathrm{~K}$, which is very small and should be attributed to uncertainties in both computations and measurements. As gravity is eliminated, the discrepancy be-

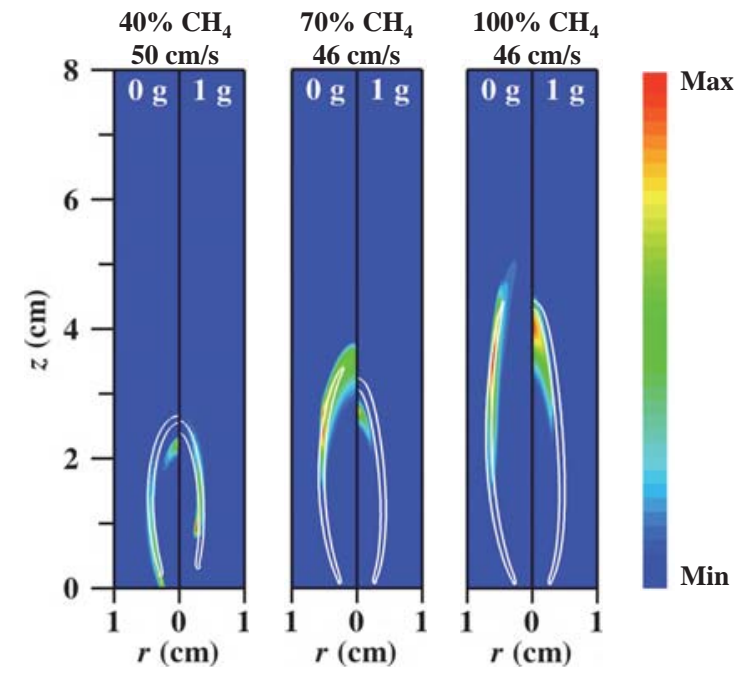

Figure 3: Typical results of computed and measured luminous flame shapes illustrating effects of fuel dilution. Color contours are measured luminous flame images, and white isopleths are computed luminous flame boundaries defined by contours of $1 \%$ of maximum $\mathrm{CH}$ concentration. Flame parameters are shown at the top of each plot.

tween computed and measured temperature fields will increase slightly, where that increment is mainly caused by the underpredicted soot volume fractions in $\mu \mathrm{g}$ [12].

Figure 3 presents a comparison between computed and measured luminous flame shapes at similar inlet velocities to demonstrate the effects of fuel dilution and gravity on flame geometry. This direct comparison was enabled by the previous observation [9] that excellent structural agreement exists between computed $\mathrm{CH}$ and measured $\mathrm{CH}^{*}$ in $\mathrm{CH}_{4}$-air diffusion flames for flame shape and lift-off height in both $\mu \mathrm{g}$ and $1 \mathrm{~g}$. Since the flames studied in our work range from lifted, non-sooting flames to attached, sooting flames, we defined the computed luminous flame boundary as the contour of $1 \%$ of maximum $\mathrm{CH}$ concentration to ensure data consistency. Regardless of the presence of soot, there is generally good agreement between computed and measured flame shapes: the computed luminous flame boundaries are located very close to the measured ones, and they capture the tendency that the flames become longer and wider as buoyancy is eliminated or fuel concentration is increased.

To quantify the effects of fuel dilution, inlet velocity, and gravity on flame shape as well as better evaluate the accuracy of the numerical model, two flame shape parameters (luminous flame length $L_{\mathrm{f}}$ and flame radius $r_{\mathrm{f}}$ ) are assessed below. Computationally, $L_{\mathrm{f}}$ is the axial dis- 


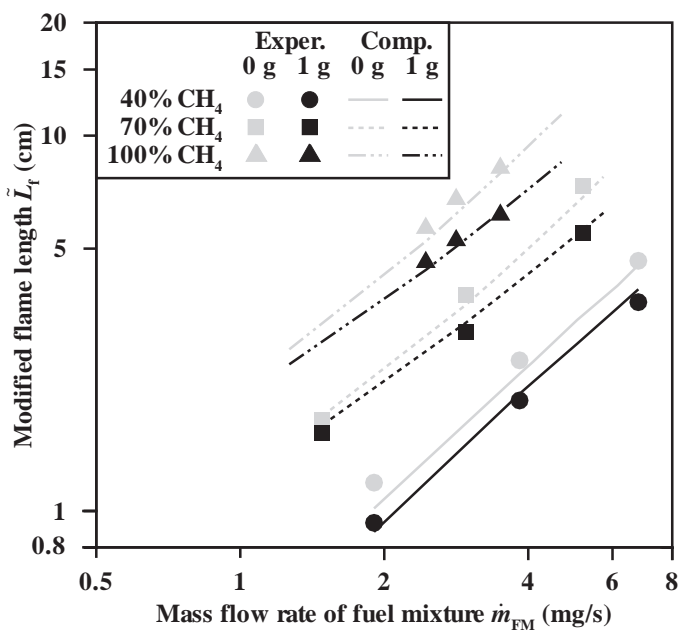

Figure 4: Computed and measured modified flame length as a function of the mass flow rate of the fuel mixture. The figure is plotted on a $\log -\log$ scale.

tance along the centerline from the burner exit plane to the point with highest $\mathrm{CH}$ concentration; and $r_{\mathrm{f}}$ is the maximum $r$ value along the computed $\mathrm{CH}$ contour. Experimentally, $L_{\mathrm{f}}$ is the axial distance along the centerline from the burner exit plane to the luminous flame boundary; and $r_{\mathrm{f}}$ is the maximum $r$ value along the measured luminous flame boundary. Since the coflow velocity is relatively small in this study, only the $40 \% \mathrm{CH}_{4}$ flame in $1 \mathrm{~g}$ is lifted and all other flames are attached. Considering that the GRI mechanism will underpredict the lift-off height of the highly diluted $40 \% \mathrm{CH}_{4}$ flames [9], and that the lift-off height can take a significant portion of the flame length at high flowrates, the modified flame length $\tilde{L}_{\mathrm{f}}$ (obtained by subtracting the lift-off height from $L_{\mathrm{f}}$ ) is employed in the current investigation to uncover better the intrinsic physics of the problem.

Computed and measured values of $\tilde{L}_{\mathrm{f}}$ are illustrated in Fig. 4. These results are plotted as a function of the mass flow rate of the fuel mixture, $\dot{m}_{\mathrm{FM}}$, based on the theory that laminar flame length should be proportional to the fuel mass flow rate [29]. Results in Fig. 4 reveal very good agreement between computed and measured $\tilde{L}_{\mathrm{f}}$, where the difference between computed and measured $\tilde{L}_{\mathrm{f}}$ is always less than $15 \%$. In $1 \mathrm{~g}$, the average slopes of the computed and measured $\tilde{L}_{\mathrm{f}}$ values with respect to $\dot{m}_{\mathrm{FM}}$ on a log-log scale are 1.02 and 1.03; while in $\mu \mathrm{g}$, the corresponding values are 1.12 and 1.07. These values reveal a strong linear dependence, and the linearity shown in Fig. 4 is in good agreement with

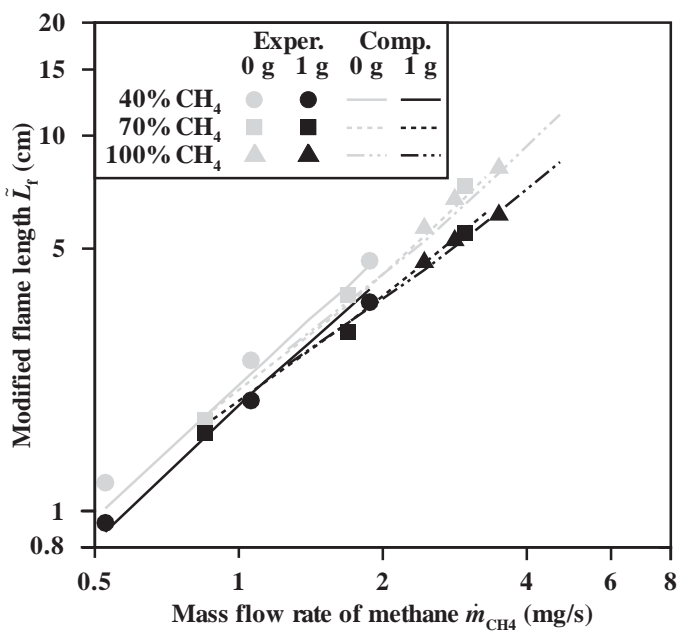

Figure 5: Computed and measured modified flame length as a function of the mass flow rate of methane. The figure is plotted on a $\log -\log$ scale.

model predictions [29] and previous investigations of buoyant $[30,31]$ and nonbuoyant flames $[3,4,7]$. It is also observed in Fig. 4 that $\mu \mathrm{g}$ flame lengths are longer than their $1 \mathrm{~g}$ counterparts, with computed and measured nonbuoyant flames $22 \%$ and $28 \%$ longer, on average, and the difference in $\tilde{L}_{\mathrm{f}}$ increases as $\dot{m}_{\mathrm{FM}}$ increases. This trend (i.e., decreasing $\tilde{L}_{\mathrm{f}}$ with increasing gravitational acceleration) has been reported previously in both microgravity flames $[3,4]$ and centrifuge flames [32].

Figure 5 shows the dependence of computed and measured $\tilde{L}_{\mathrm{f}}$ on the mass flow rate of just the methane, $\dot{m}_{\mathrm{CH}_{4}}$. We found that $\tilde{L}_{\mathrm{f}}$ is predominantly controlled by $\dot{m}_{\mathrm{CH}_{4}}$ in both $\mu \mathrm{g}$ and $1 \mathrm{~g}$, and that the fuel stream dilution has negligible influence on $\tilde{L}_{\mathrm{f}}$. The overpredicted flame length of the $40 \% \mathrm{CH}_{4}$ buoyant flame at $\dot{m}_{\mathrm{CH}_{4}} \approx 2 \mathrm{mg} / \mathrm{s}$ is mainly caused by the underpredicted lift-off height, which is a known limitation of the GRI mechanism and has been reported previously [9]. On the other hand, as the corresponding $40 \% \mathrm{CH}_{4}$ flame in $\mu \mathrm{g}$ is attached, we are able to avoid underpredicting its lift-off height and thus can predict its length correctly. The predominant effects of $\dot{m}_{\mathrm{CH}_{4}}$ on the velocity field and flame structure will be further examined in the context of Figs. 7-9.

The computed and measured flame radii are shown in Fig. 6. Very good agreement was obtained between computations and measurements for most flames, and the largest discrepancy between computed and measured flame radii is $29 \%$ (i.e., $0.11 \mathrm{~cm}$ ). The measured $1 \mathrm{~g} r_{\mathrm{f}}$ decreases when the $\mathrm{CH}_{4}$ concentration is in- 


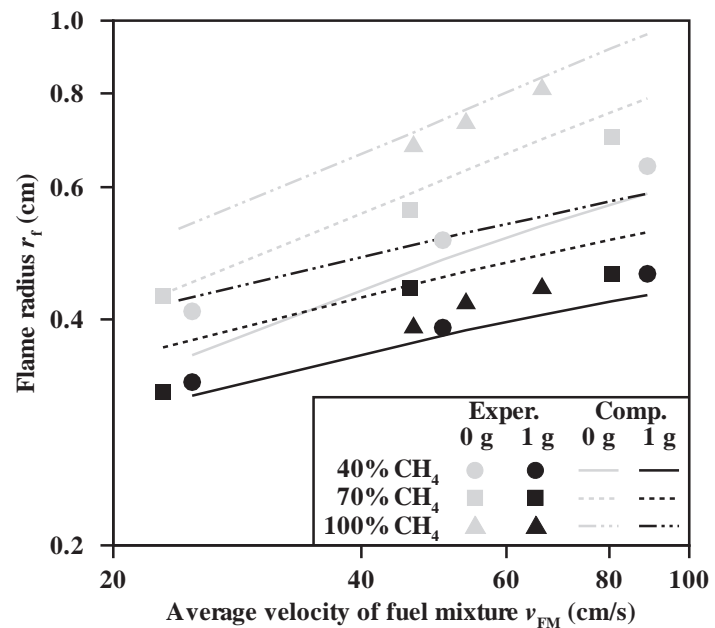

Figure 6: Computed and measured flame radius as a function of the average velocity of the fuel mixture. The figure is plotted on a log-log scale.

creased from $70 \%$ to $100 \%$. This behavior is caused by the shift of the dominant luminosity from $\mathrm{CH}^{*}$ chemiluminescence to soot emission as depicted in Fig. 3. In $1 \mathrm{~g}$, the average slopes of the computed and measured $r_{\mathrm{f}}$ values with respect to the average velocity of the fuel mixture, $v_{\mathrm{FM}}$, on a log-log scale are 0.25 and 0.27 , which is in good agreement with the theoretical prediction that $r_{\mathrm{f}} \propto \mathrm{St}^{0.25}$ (where $\mathrm{St}=\mathrm{Fr} / \mathrm{Re}$, the source Stokes number) [29, 31]. In $\mu \mathrm{g}$, the corresponding values are 0.43 and 0.39 , and they are closer to the expression that $r_{\mathrm{f}} \propto v_{\mathrm{FM}}^{0.5}$ from Lin and Faeth for non-buoyant flames with constant coflow velocity and reactant conditions [6]. It is also observed in Fig. 6 that $\mu \mathrm{g}$ flames are considerably wider than the corresponding $1 \mathrm{~g}$ flames. The difference in $r_{\mathrm{f}}$ is presumably due to the radially inward convection that moves the flame front towards the centerline; this inward flow is clearly illustrated by the light blue region outside the stoichiometric mixture fraction contour in Fig. 8.

Figure 7 shows the dependence of computed and measured flame radii on the mass flow rate of just the methane, $\dot{m}_{\mathrm{CH}_{4}}$. Similar to Fig. 5, it is observed that the flame radius is mainly controlled by the fuel mass flow rate in both $\mu \mathrm{g}$ and $1 \mathrm{~g}$, and that the effects of fuel stream dilution on $r_{\mathrm{f}}$ is secondary.

Figure 8 illustrates the effects of gravity, fuel dilution and inlet velocity on the velocity field and flame structure. In each plot, the $\mu \mathrm{g}$ velocity field is plotted on the left and its $1 \mathrm{~g}$ counterpart is depicted on the right.

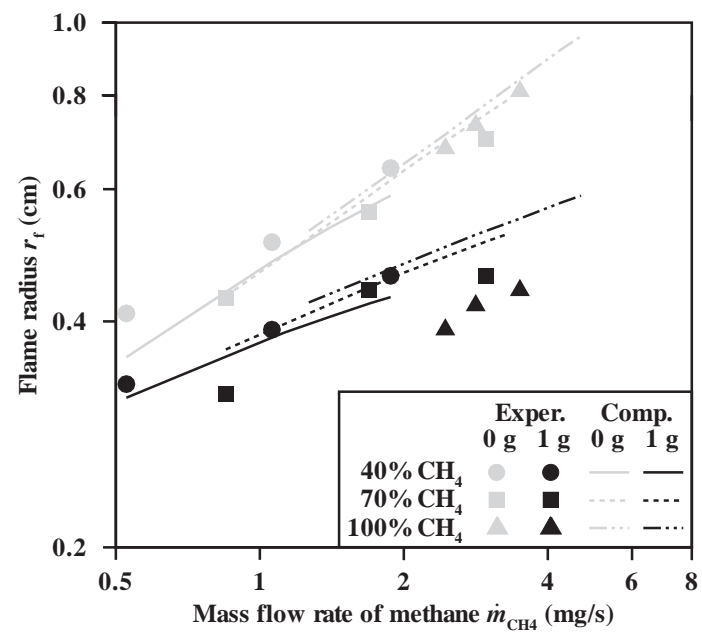

Figure 7: Computed and measured flame radius as a function of the mass flow rate of methane. The figure is plotted on a log-log scale.

We immediately observe that gravity has a profound effect on the velocity field. In $1 \mathrm{~g}$, the magnitude of the velocity continues to increase with increasing $z$ position, and the radial distribution of the velocity field changes from bell-shaped near the burner exit plane to parabolic in the post-flame region. In $\mu \mathrm{g}$, the velocity field shows a completely different behavior: the magnitude of the velocity decreases with increasing $z$ position, and the radial distribution of the velocity field becomes more uniform. This discrepancy is mainly caused by the absence of buoyancy-induced acceleration and the increased radial diffusion of momentum, and it becomes more pronounced as the flow proceeds downstream. The $v_{r}$ profiles (color contours) are remarkably affected by gravity as well. When buoyancy is eliminated, the region near the burner exit plane with positive $v_{r}$ (mainly due to thermal expansion) becomes more intense and has a larger area; the radially inward flow outside the flame front (represented by the stoichiometric mixture fraction contour) disappears, and the flame becomes wider and longer.

The predominant influence of methane mass flow rate on the flame structure is also demonstrated in Fig. 8 by the $70 \% \mathrm{CH}_{4}$ flame with $v_{\mathrm{FM}}=66 \mathrm{~cm} / \mathrm{s}$ and the $100 \% \mathrm{CH}_{4}$ flame with $v_{\mathrm{FM}}=46 \mathrm{~cm} / \mathrm{s}$, as these two flames have approximately the same $\dot{m}_{\mathrm{CH}_{4}}$ values. From Fig. 8, it is observed that their flame fronts have very similar shapes and dimensions in both $\mu \mathrm{g}$ and $1 \mathrm{~g}$, and that their velocity fields in the vicinity of the centerline become nearly indistinguishable when 


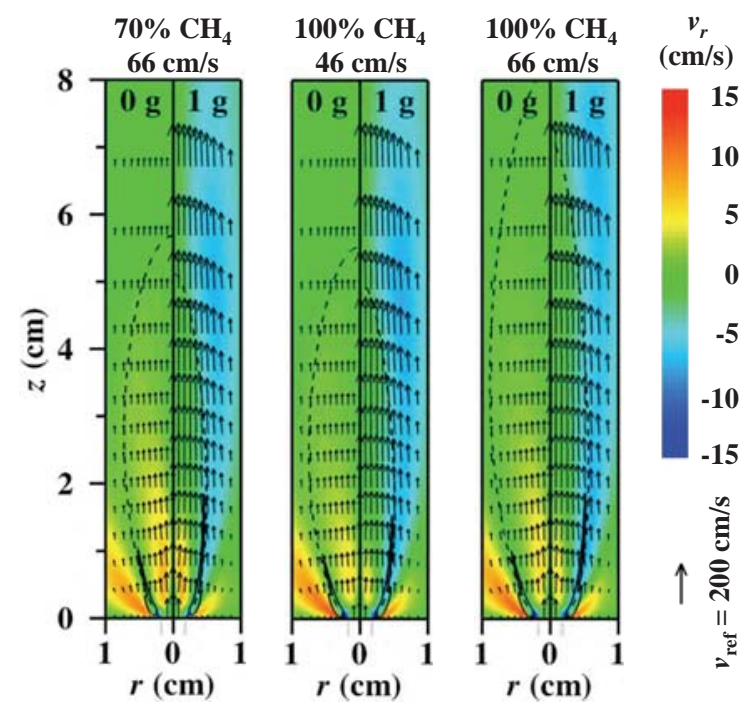

Figure 8: Effects of inlet velocity, fuel dilution, and gravity on radial velocity distribution (in color contours) and velocity vectors. Also plotted are heat release rate at $\dot{q}=100 \mathrm{~W} / \mathrm{cm}^{3}$ (solid black isopleth), and stoichiometric mixture fractions (dashed black isopleths). Flame parameters are shown at the top of each plot. Note that the color distribution in the legend was modified to emphasize the radial convection near the flame front.

$z \geq 3 \mathrm{~cm}$ (i.e., the centerline velocities are within $10 \%$ of each other). We subsequently investigate the effects of fuel dilution on the velocity field by examining the $70 \%$ and $100 \% \mathrm{CH}_{4}$ flames with $v_{\mathrm{FM}}=66 \mathrm{~cm} / \mathrm{s}$. We observe that as the fuel concentration increases, the flame becomes larger and more exothermic, and it generates a more intense radially inward flow. Since more heat is generated, the $1 \mathrm{~g}$ velocity field will have a larger magnitude in the post-flame region. The thermal expansion of the flow near the burner exit plane becomes enhanced too, illustrated by a larger region of flow having a higher radial velocity and the stronger radially inward flow inside the heat release contour (the blue dot near the fuel tube). The influence of increasing $v_{\mathrm{FM}}$ is similar to that of increasing fuel concentration, because both processes lead to an increase in $\dot{m}_{\mathrm{CH}_{4}}$.

Finally, we examine the distributions of temperature, axial velocity, and residence time along the centerline. Results shown in Fig. 9 indicate that when buoyancy is eliminated, the peak temperature along the centerline drops by around $300 \mathrm{~K}$ and moves downstream, with larger changes occurring in flames with higher fuel concentration or higher inlet velocity. Gravity also has a profound effect on the velocity field. Since $v_{z} \propto z^{0.5}$ [29], the difference between $v_{z}$ in $\mu \mathrm{g}$ and $1 \mathrm{~g}$
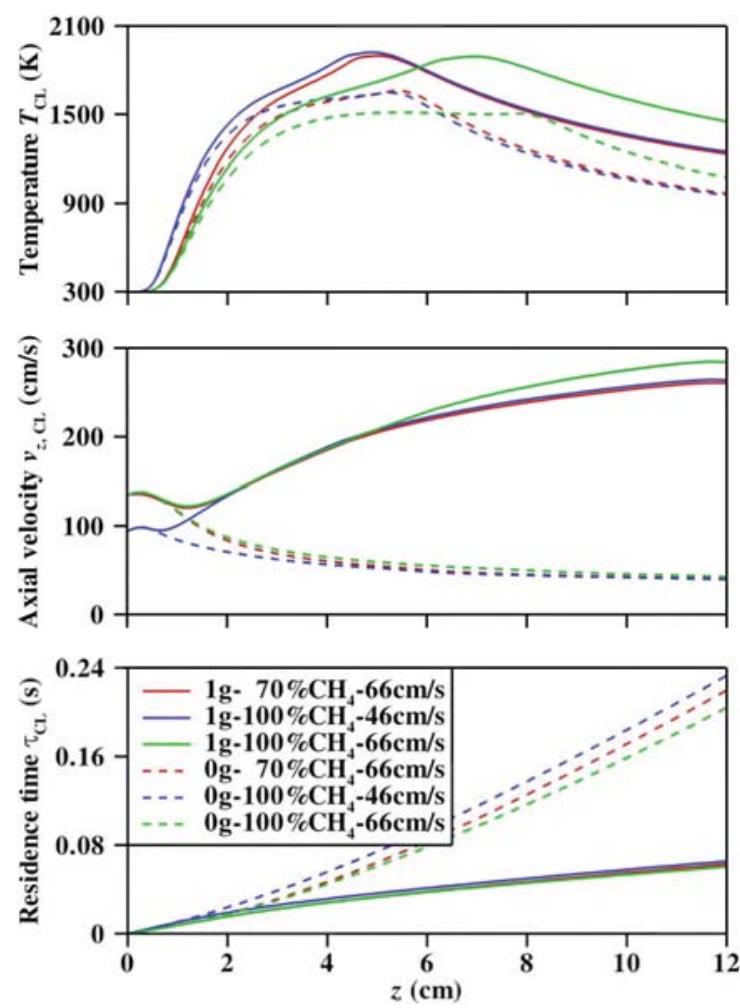

Figure 9: Temperature $T_{\mathrm{CL}}$, axial velocity $v_{z, \mathrm{CL}}$, and residence time $\tau_{\mathrm{CL}}$ along the centerline as a function of height for the three pairs of flames discussed in the context of Fig. 8.

in the vicinity of the centerline increases as $z$ increases, and this difference will result in a 3.5-fold increase in residence time $\tau_{\mathrm{CL}}$ near the domain exit, as shown in Fig. 9. The dominant influence of methane mass flow rate is also observed: the centerline temperature and axial velocity of the $70 \% \mathrm{CH}_{4}$ flame with $v_{\mathrm{FM}}=66 \mathrm{~cm} / \mathrm{s}$ and the $100 \% \mathrm{CH}_{4}$ flame with $v_{\mathrm{FM}}=46 \mathrm{~cm} / \mathrm{s}$ are very similar in both $\mu \mathrm{g}$ and $1 \mathrm{~g}$, and they differ significantly from the results of the $100 \% \mathrm{CH}_{4}$ flame with $v_{\mathrm{FM}}=66 \mathrm{~cm} / \mathrm{s}$.

\section{Conclusions}

Effects of fuel dilution, inlet velocity, and gravity on the shape and structure of laminar coflow $\mathrm{CH}_{4}$-air diffusion flames were investigated computationally and experimentally, with very good agreement obtained. The major conclusions were as follows. (1) Buoyant and nonbuoyant luminous flame lengths are proportional to the mass flow rate of the fuel mixture; computed and 
measured nonbuoyant flames are noticeably longer than their $1 \mathrm{~g}$ counterparts; the effect of fuel dilution on flame shape (i.e., flame length and flame radius) is negligible when the flame shape is normalized by the methane flow rate. (2) Buoyancy-induced reduction of the flame radius through radially inward convection near the flame front is demonstrated. (3) Buoyant and nonbuoyant flame structure is mainly controlled by the fuel mass flow rate, and the effects of fuel dilution and inlet velocity are secondary. In addition to studying the behavior of flames with other fuels such as ethylene, future work will likely focus on the dependence of flame structure and sooting behavior on coflow velocity and fuel tube diameter.

\section{Acknowledgments}

This research was supported by NASA, the US Department of Energy Office of Basic Energy Sciences (Dr. Wade Sisk, contract monitor), the National Science Foundation (Dr. Phil Westmoreland, contract monitor), and the US Air Force Office of Scientific Research (Dr. Fariba Fahroo and Dr. Misoon Mah, contract monitors), under contracts NNX11AP43A, DE-FG0288ER13966, CTS-0328296, AFOSR FA9550-06-10164, and AFOSR FA9550-09-1-0571, respectively. We are also grateful to Dr. Donald R. Pettit for conducting the SLICE tests on the International Space Station.

\section{References}

[1] G.M. Faeth, in Microgravity Combustion: Fire in Free Fall (H.D. Ross, Ed.), Academic Press, San Diego 2001.

[2] R.W. Bilger, Combust. Flame 30 (1977) 277-284.

[3] M.Y. Bahadori, R.B. Edelman, D.P. Stocker, S.L. Olson, AIAA J. 28 (1990) 236-244.

[4] M.Y. Bahadori, D.P. Stocker, D.F. Vaughan, L. Zhou, R.B. Edelman, in Modern Developments in Energy, Combustion and Spectroscopy (F.A. Williams et al., Eds.), Pergamon, New York, 1993.

[5] I. Glassman, Proc. Combust. Inst. 27 (1998) 1589-1596.

[6] K.-C. Lin, G.M. Faeth, AIAA J. 37 (1999), 759-765.

[7] P.B. Sunderland, B.J. Mendelson, Z.G. Yuan, D.L. Urban, Combust. Flame 116 (3) (1999) 376-386.

[8] K.T. Walsh, J. Fielding, M.D. Smooke, M.B. Long, Proc. Combust. Inst. 28 (2000) 1973-1979.

[9] K.T. Walsh, J. Fielding, M.D. Smooke, M.B. Long, A. Liñán, Proc. Combust. Inst. 30 (2005) 357-365.

[10] S.K. Aggarwal, Prog. Energy Combust. Sci. 35 (6) (2009) 528570.

[11] M.R.J. Charest, C.P.T. Groth, Ö.L. Gülder, Combust. Flame 158 (5) (2011) 860-875

[12] B. Ma, S. Cao, D. Giassi, D.P. Stocker, F. Takahashi, B.A.V. Bennett, M.D. Smooke, M.B. Long, (submitted to Proc. Combust. Inst. 35).

[13] B.A.V. Bennett, M.D. Smooke, Combust. Theory Model. 2 (1998) 221-258.
[14] B.A.V. Bennett, C.S. McEnally, L.D. Pfefferle, M.D. Smooke, Combust. Flame, 123 (4) (2000) 522-546.

[15] M.D. Smooke, R.J. Hall, M.B. Colket, J. Fielding, M.B. Long, C.S. McEnally, L.D. Pfefferle, Combust. Theory Model. 8 (3) (2004) 593-606.

[16] M.D. Smooke, M.B. Long, B.C. Connelly, M.B. Colket, R.J. Hall, Combust. Flame, 143 (4) (2005) 613-628.

[17] S. Cao, B.A.V. Bennett, M.D. Smooke, in preparation.

[18] V. Giovangigli, N. Darabiha, in: C.-M. Brauner, C. SchmidtLainé (Eds.), Mathematical Modeling in Combustion and Related Topics, Nijhoff, Dordrecht, 1988, pp. 491-503.

[19] G.P. Smith, D.M. Golden, M. Frenklach, N.W. Moriarty, B. Eiteneer, M. Golderberg, C.T. Bowman, R.K. Hanson, S. Song, W.C. Gardiner, Jr., V.V. Lissianski, Z. Qin, GRI-Mech 3.0, 1999; available at $<$ http://www.me.berkeley.edu/gri_mech $>$.

[20] R.J. Hall, M.D. Smooke, M.B. Colket, in Physical and Chemical Aspects of Combustion: A Tribute to Irvin Glassman (R.F Sawyer and F.L. Dryer, Eds.), Combustion Science and Technology Book Series, Gordon and Breach, Amsterdam 1997.

[21] F.S. Liu, H.S. Guo, G.J. Smallwood, Combust. Flame, 138 (1-2) (2004) 136-154.

[22] D.K. Edwards, Adv. Heat Transfer 12 (1976) 115-193.

[23] R.J. Hall, J. Quant. Spectrosc. Radiat. Transfer 49 (5) (1993) 517-523.

[24] P. Deuflhard, Numerische Mathematik 22 (4) (1974) 289-315.

[25] M.D. Smooke, J. Optim. Theory Appl. 39 (4) (1983) 489-511.

[26] H.A. van der Vorst, SIAM J. Sci. Stat. Comput. 13 (2) (1992) 631-644.

[27] P.B. Kuhn, B. Ma, B.C. Connelly, M.D. Smooke, M.B. Long, Proc. Combust. Inst. 33 (2011) 743-750.

[28] B. Ma, G. Wang, G. Magnotti, R.S. Barlow, M.B. Long, Combust. Flame, 161 (4) (2014) 908-916.

[29] F.G. Roper, Combust. Flame 29 (1977) 219-226.

[30] R.E. Mitchell, A.F. Sarofim, L.A. Clomburg, Combust. Flame 37 (1980) 227-244.

[31] K. Saito, F.A. Williams, A.S. Gordon, Combust. Sci. Technol. 47 (3-4) (1986) 117-138.

[32] R.A. Altenkirch, R. Eichhorn, N.N. Hsu, A.B. Brancic, N.E Cevallos, Proc. Combust. Inst. 16 (1976) 1165-1174. 